\title{
ChickRH6: a chicken whole-genome radiation hybrid panel
}

\author{
Mireille Morisson*, Alexandre Lemière, Sarah Bosc, \\ Maxime Galan, Florence Plisson-Petit, Philippe Pinton, \\ Chantal Delcros, Katia Fève, Frédérique Pitel, Valérie Fillon, \\ Martine Yerle, Alain Vignal
}

Laboratoire de génétique cellulaire, Institut national de la recherche agronomique, 31326 Castanet-Tolosan, France

(Received 4 February 2002; accepted 13 May 2002)

\begin{abstract}
As a first step towards the development of radiation hybrid maps, we have produced a radiation hybrid panel in the chicken by fusing female embryonic diploid fibroblasts irradiated at 6000 rads with HPRT-deficient hamster $\mathrm{Wg}_{3} \mathrm{hCl}_{2}$ cells. Due to the low retention frequency of the chicken fragments, a high number of clones was produced from which the best ones were selected. Thus, 452 fusion clones were tested for retention frequencies with a panel of 46 markers. Based on these results, 103 clones with a mean marker retention of $23.8 \%$ were selected for large scale culture to produce DNA in sufficient quantities for the genotyping of numerous markers. Retention frequency was tested again with the same 46 markers and the 90 best clones, with a final mean retention frequency of $21.9 \%$, were selected for the final panel. This panel will be a valuable resource for fine mapping of markers and genes in the chicken, and will also help in building BAC contigs.
\end{abstract}

chicken / radiation hybrid / mapping

\section{INTRODUCTION}

The interest in studying the chicken genome has greatly increased in the past years, driving international efforts towards detailed physical and genetic maps (for a review, see [29]). One of the reasons for this interest is the importance of this species in agriculture. The various current efforts aiming at mapping QTLs (quantitative trait loci), involved in production traits and the resistance to pathogens, will benefit greatly from detailed knowledge of the genome. Other reasons include the importance of the chicken in evolutionary studies as a model organism for birds, and in developmental biology. Also, the chicken

\footnotetext{
* Correspondence and reprints

E-mail: mmorisso@toulouse.inra.fr
} 
has the typical genome organisation of birds, with two chromosome subtypes: nine pairs of cytogenetically distinguishable macrochromosomes including the two sex chromosomes Z and W [19] and 30 pairs of small, cytogenetically indistinguishable microchromosomes. The female is the heterogametic sex (ZW) and the male is the homogametic sex (ZZ). The estimated haploid genome size of the chicken is close to $1.2 \times 10^{9} \mathrm{bp}$ [2].

Apart from having a small size, estimated to being between 7 and $23 \mathrm{Mb}$ [2], the microchromosomes appear to be more gene dense than the macrochromosomes $[3,24,30]$ and to show a higher rate of recombination $[9,25,28]$. Twenty-two pairs of them have now been identified by using large insert clones in FISH (fluorescence in situ hybridisation) experiments ([8,29], Fillon et al., in preparation).

A consensus genetic map containing close to 1900 loci was published [12], consisting of 50 linkage groups, with some of them containing as little as two markers. Despite the efforts made to integrate the genetic and cytogenetic maps of the chicken chromosomes [25,31], 16 of the small linkage groups still have to be assigned to a chromosome. The fact that the number of linkage groups is still higher than that of the chromosomes is probably a consequence of the very high recombination rates associated to the microchromosomes, impeding linkage association.

Two BAC libraries were constructed in the chicken $[5,20]$ and a large amount of chicken ESTs were produced [1,34], (see also: http://chick.umist.ac.uk, http://www.chickest.udel.edu).

In this context, whole-genome radiation hybrid (WGRH) panels provide a complementary approach to the different genome mapping techniques currently used in chicken. The resolution that can be achieved is higher than that obtained with recombinant mapping, enabling the ordering of markers otherwise clustered on the genetic map. Another interesting point is the possibility to map markers by a simple PCR, avoiding the necessary development of polymorphism as required for genetic maps. Therefore, the mapping of the now available high numbers of ESTs can be streamlined. The potential resolution of a radiation hybrid panel is tailored by the radiation dose, and panels of different resolutions can be created depending on the needs: aid to BAC contig construction, high resolution transcript maps of a whole genome, or regional fine mapping of candidate regions for QTLs.

WGRH panels are now available in many species including human [13,27, 33], mouse [23], rat [22], dog [35], cat [26], cow [37], pig [38] and horse [17]. Zebrafish WGRH panels and RH maps have been published [11,14], demonstrating that RH technology can also be used for non-mammalian vertebrates. Recently, a first collection of 48 chicken radiation hybrids was published [18]. However, the number of clones produced, the retention frequencies per clone and the DNA quantities available were too low and also varying parameters 
such as different radiation doses and recipient cell lines were used. The heterogeneity of the clones thus obtained, with variations in breakage and retention frequencies, may cause problems for the mapping process.

We report here the production of a chicken whole-genome radiation hybrid panel, obtained by fusing irradiated female embryonic diploid fibroblasts to a HPRT-deficient hamster cell line $\left(\mathrm{Wg} 3 \mathrm{hCl}_{2}\right)$. A radiation dose of 6000 rads was chosen as a compromise between resolution power and linkage power to build a first chicken RH map. Due to the low retention rate of the chicken genome in the hybrids, a large number of clones (452) was produced, from which the selection of the best ones was performed by using a set of 46 markers chosen across the genome from the genetic map. Ninety hybrids were selected to build the final panel.

\section{MATERIALS AND METHODS}

\subsection{Generation of radiation hybrids}

The method was adapted from the one first described by Walter et al. [36] and widely used [22,38]. The chicken donor cells used for constructing this panel were normal diploid fibroblasts. They were obtained from six different 9-day-old female chick embryos and propagated in complete RPMI media [RPMI1640 (Sigma Chemical Co.) supplemented with 15\% foetal calf serum (Life Technologies), streptomycin and penicillin]. During each experiment, $2 \times 10^{7}$ cells were suspended in $20 \mathrm{~mL}$ of RPMI 1640 and irradiated at 6000 rads by gamma rays from a Cesium- 137 source. They were mixed to the same number of recipient cells of the hypoxanthine guanine phosphoribosyl transferase (HPRT)-deficient hamster cell line, $\mathrm{Wg}_{3} \mathrm{hCl}_{2}$ [7]. Fusion partners were first pelleted and then suspended in $1 \mathrm{~mL}$ of polyethyleneglycol (Roche Diagnostics $\mathrm{GmbH})$. After $1 \mathrm{~min}, 40 \mathrm{~mL}$ of RPMI without serum were gradually added and $1 \mathrm{~mL}$ of this fusion mixture was added to forty $75-\mathrm{cm}^{2}$ flasks containing $30 \mathrm{~mL}$ of the complete RPMI media. Twenty-four hours after fusion, HAT (hypoxanthine-aminopterin-thymidine) was added to the media. Four days later, the whole media was changed to discard the non-fused cells. Eight to ten days after the fusion the first hybrid clones were observed. When fully grown after 8 to 20 days of culture, they were picked and transferred to $25-$ $\mathrm{cm}^{2}$ flasks. The cells were subsequently transferred to two $75-\mathrm{cm}^{2}$ flasks. In order to limit the number of doubling events and the possible loss of chicken genome fragments, all the cells in a flask were passaged. Finally, the cells were harvested from the two $75-\mathrm{cm}^{2}$ flasks. Five million were used to extract DNA and the rest were cryopreserved. 


\subsection{Estimation of chromosome retention frequency}

Hybrids were screened for the presence of chicken DNA by using a set of 46 markers distributed across the genome. All of them were microsatellite markers except the XhoI-family marker from chromosome W [4]: the primer sequences are available at http://www.ri.bbsrc.ac.uk/chickmap/ChickMapHomePage.html.

The PCR reaction contained $25 \mathrm{ng}$ hybrid DNA, $2 \mathrm{mM} \mathrm{MgCl} 2,0.3 \mathrm{U}$ Taq DNA polymerase (Life technologies), $1 \mathrm{X}$ buffer (Life technologies), $0.05 \mathrm{X}$ $1 \% \mathrm{~W}-1$ (Life technologies), $200 \mu \mathrm{M}$ of each dNTPs, $0.2 \mu \mathrm{M}$ of each primer and $1 \mathrm{X}$ loading buffer ( $350 \mathrm{mM}$ sucrose and $0.2 \mathrm{mM}$ cresol red) in a total volume of $15 \mu \mathrm{L}$.

The PCR protocol used for the marker XhoI was the one described by Clinton (1994) [4], while for the microsatellite markers, a touch-down PCR protocol [6] was performed: denaturation at $94^{\circ} \mathrm{C}$ for 3 min was followed by two cycles at each annealing temperature of $57^{\circ} \mathrm{C}$ and $55^{\circ} \mathrm{C}$ and 33 cycles with an annealing temperature of $53^{\circ} \mathrm{C}\left(30 \mathrm{~s}\right.$ at the annealing temperature, $20 \mathrm{~s}$ at $72{ }^{\circ} \mathrm{C}$ and $30 \mathrm{~s}$ at $94^{\circ} \mathrm{C}$ ).

PCR products were analysed using $2 \%$ agarose gels and were visualised using ethidium bromide staining. All markers were genotyped in duplicate and scored for the presence or absence of PCR products.

\subsection{Large scale culture (LSC)}

One hundred and three hybrids were selected based on their high retention rate and cultured in a large scale at the Centre d'étude du polymorphisme humain (Dr Claudia de Toma, Fondation Jean Dausset - CEPH - 27, rue Juliette Dodu, 75010 Paris, France). Cryopreserved seed stocks were used to inoculate one $75-\mathrm{cm}^{2}$ flask. The cells were subsequently transferred to eight roller bottles to produce the final harvest for DNA extraction. The retention frequencies of these 103 hybrids were then re-evaluated using the same 46 markers as before, to select the 90 best ones in the final panel.

\section{RESULTS}

\subsection{Generation and characterisation of 452 whole genome radiation hybrids}

Fifteen fusion experiments were carried out to produce 452 chicken wholegenome radiation hybrids. One clone was recovered per 720000 chicken fibroblasts, corresponding to a fusion efficiency of approximately $1.4 \times 10^{-6}$ clones per chicken fibroblast. 


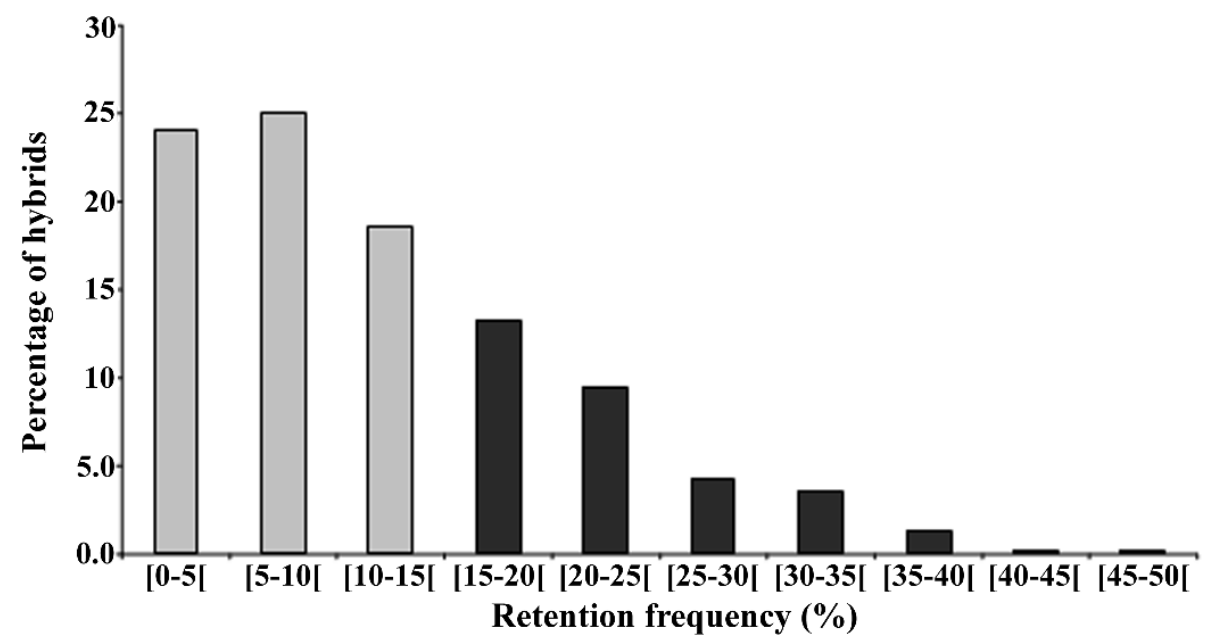

Figure 1. Distribution of the 452 hybrids depending on their retention frequency. Most of the hybrids (67.7\%) showed an average retention frequency below $15 \%$. Only $32.3 \%$ of the hybrids were satisfactory candidates for the final panel. [0-5[: retention frequencies below $5 \%$.

[5-10[: comprised between 5\% and 9.99\%.

To determine the extent to which donor fragments were retained in our hybrids, 46 markers were amplified by PCR from DNA obtained from each of them. Due to the particularities of the chicken genome structure, care was taken in the choice of markers to represent all chromosome types. Half of the markers were from macrochromosomes 1 to 8 and the gonosomes. When several markers from the same chromosomes were used, they were chosen at a minimum distance of $8 \mathrm{cM}$ from one another. Sixteen other markers were from linkage groups assigned to identified microchromosomes. The seven last markers were from undefined regions of the genome: two were from small linkage groups, supposedly corresponding to two different microchromosomes, and five were not linked to any other marker or linkage group in the actual consensus linkage map of the chicken [12]. We supposed that these last markers belong to the smallest microchromosomes and we therefore analysed the results considering two classes of markers: 23 localised on macrochromosomes and 23 localised on microchromosomes.

The average retention rate of the 452 hybrids was $11.3 \%$ for the whole genome, but the overall retention rate for markers located on microchromosomes was higher (14.8\%) as compared to that of macrochromosomes (9.5\%).

Thus, only $32.3 \%$ of the hybrids showed a whole genome retention frequency higher than $15 \%$ and could be considered as potential candidates for the final mapping panel (Fig. 1). No higher retention frequency could be observed on 
chromosome 4 bearing HPRT [10], since the chromosome 4 markers used in this study were not close to this gene. The two haploid markers located on chromosome $\mathrm{Z}$ showed retention frequencies lower than the others, due to the use of female chicken donor cells while the XhoI marker was better retained among the hybrids reflecting its location close to a centromere (Fig. 2). Indeed, the cytogenetic assignment for this marker was proposed to be in Wp1.2-q1.1 by Solari et al. [32].

\subsection{Pre-selection of $\mathbf{1 0 3}$ candidate hybrids}

Considering the low average retention frequency of the chicken-hamster hybrids, as many as 452 clones were produced, with the aim of a final panel of 90. Our first estimations of the chicken genome loss in the hybrids after large scale culture, was around 10\%. Therefore, we decided to grow the 103 best candidate hybrids in large scale culture (LSC), in order to be able to choose 90 of them for the definitive panel. As compared to the 452 hybrids, this preselection improved the overall whole genome retention frequency from $11.3 \%$ to $23.8 \%$, the overall macrochromosome retention frequency from $9.5 \%$ to $21.5 \%$ and the microchromosome one from $14.8 \%$ to $28.5 \%$ (Fig. 3).

\subsection{Selection of the 90 hybrids for the final panel}

After LSC, the retention frequencies of the 103 pre-selected hybrids were estimated using the same 46 markers. The average retention rate was $20.9 \%$ for the whole genome, but the overall retention rate for the markers located on the macrochromosomes was $18.6 \%$ and for the markers located on the microchromosomes, $25.7 \%$ (Fig. 3). The average fragment loss reached $12.5 \%$ for the whole genome: $13.5 \%$ for the macrochromosomes and $10 \%$ for the microchromosomes.

We finally selected the 90 hybrids that constitute the definitive panel. The average retention rates are $21.9 \%$ for the whole genome, $20.1 \%$ for the macrochromosomes and $25.7 \%$ for the microchromosomes (Fig. 3). However, the retention was not always so uniform, with lower values for the largest chromosomes: $15.3 \%$ for GGA1 and $17.1 \%$ for GGA2.

Two control DNAs were included in the panel: the $\mathrm{Wg} 3 \mathrm{hCl}_{2}$ hamster cell line DNA and a chicken DNA that is a mix of two female embryonic chicken DNAs.

\section{CONCLUSIONS}

A fusion efficiency of approximately $1.4 \times 10^{-6}$ clones per chicken fibroblast was observed. This fusion efficiency was low in comparison to that of 

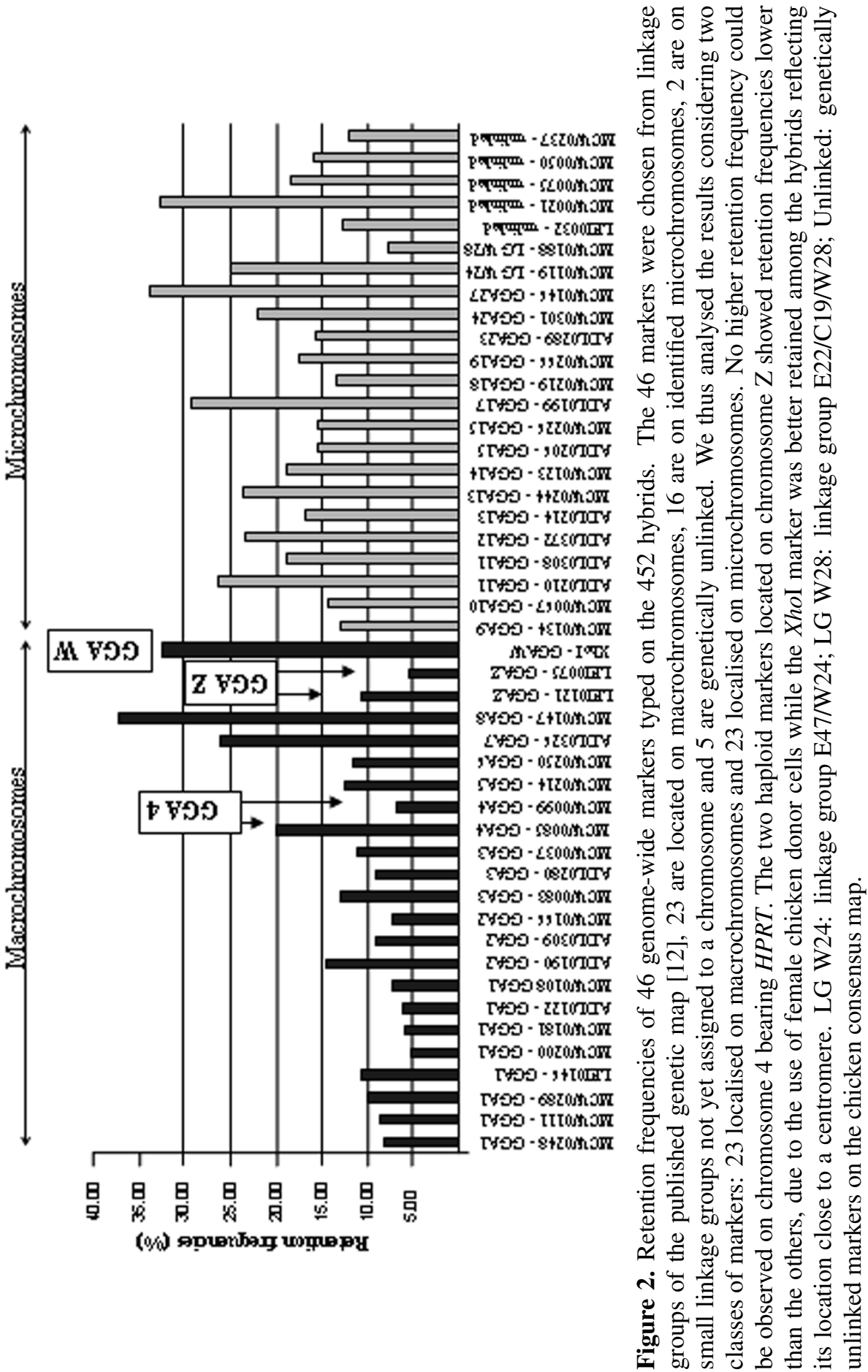


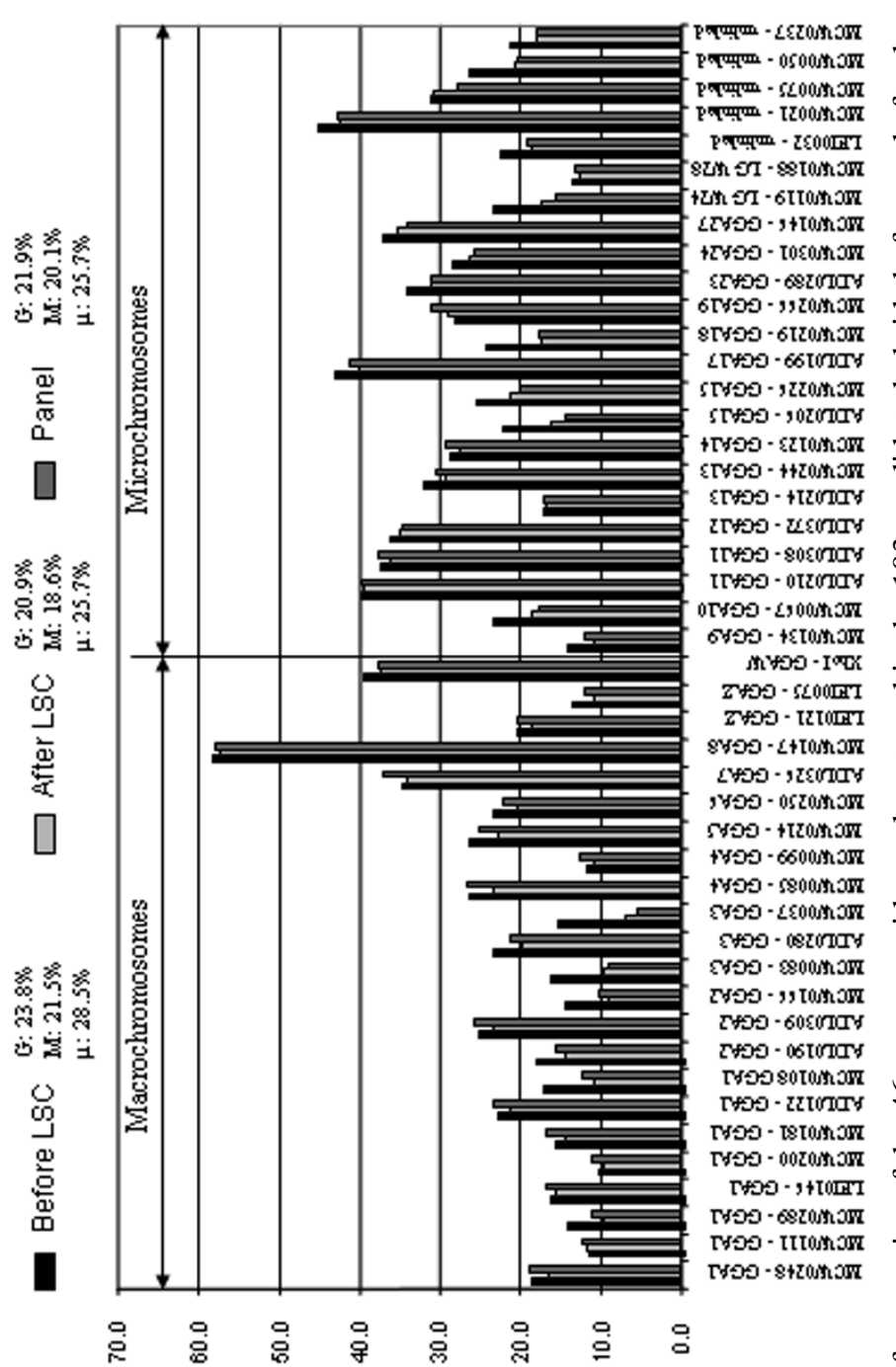

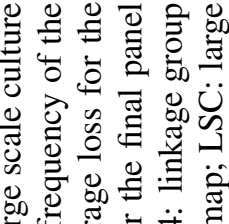

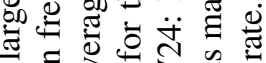
$\bar{\phi} \cdot \overline{0}$ o 3 क

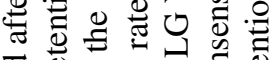
를 ส 0.0

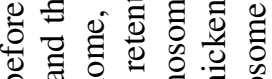
0 记

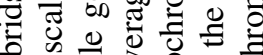

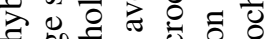

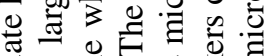
氝 궁ㅎㅇ บ 0 웅 $m \equiv 00$ do ป ก

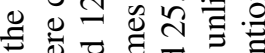

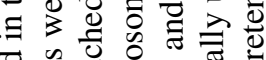
응 0 त

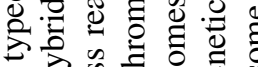
元令

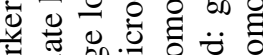

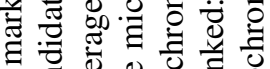

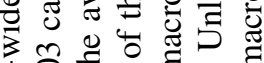

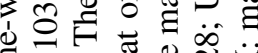

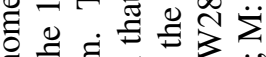
ปิ

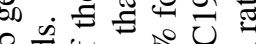

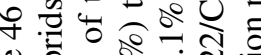

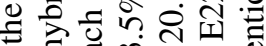
ড๐き

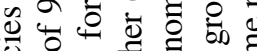

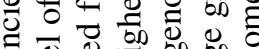
ब

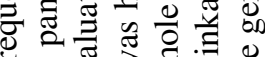

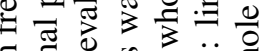

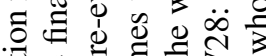

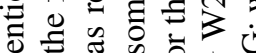
य

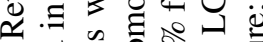

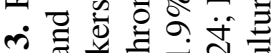
ช

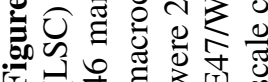


mammals, e.g. $10^{-5}$ in dogs [35] and $10^{-4}$ in human [36]. This was expected given the evolutionary distance of the two species, and the results obtained by others ([18], Bumstead, personal communication).

The average retention rate of the 452 hybrids was $11.3 \%$ for the whole genome, but the overall retention rate for the markers located on the microchromosomes was higher $(14.8 \%)$ as compared to that of the macrochromosomes (9.5\%). These results were in accordance with those of Kwock et al. [18], where retention frequencies were $17.8 \%$ for microchromosomes and $10.6 \%$ for macrochromosomes. It has been observed that smaller chromosomes are generally retained at a higher rate, as e.g. in a human WGRH panel [13]. In the chicken, where the difference in size between the macrochromosomes and the microchromosomes is more pronounced, this trend is more evident. One possible explanation is that in a microchromosome, markers are usually at a closer distance to a centromere, a region where retention frequencies have been shown to be high [15].

For both practical and economical reasons, reducing the number of hybrid DNA samples in a panel to the number that can be easily handled in a microplate is highly desirable. Theoretical data have been reported on the consequences of hybrid selection on the mapping power of RH panels and it is generally admitted that a retention frequency over $20 \%$ is a minimum prerequisite for a good efficiency of a panel $[16,21,35]$. Despite a drastic selection (90 hybrids selected out of 452 developed), we could not manage to improve the retention frequency of the two largest macrochromosomes to reach $20 \%$. However, the overall retention frequency of this panel remains suitable for RH mapping. DNA extraction produced more than $3 \mathrm{mg}$ of DNA for each hybrid, an amount sufficient for an estimated $150000 \mathrm{PCR}$ assuming $20 \mathrm{ng}$ per reaction.

This RH panel is a powerful tool for integrating genetic and physical maps. Mapping STSs from BAC contig ends will help find the location and orientation of linkage groups. An obvious exploitation is the mapping of cDNAs and ESTs onto a framework of microsatellite markers, providing the basis for the biological characterisation of specific chromosomal regions of interest. Such RH-mapping data will also be a powerful method in comparative gene mapping since chromosomal order can be established for expressed genes that are usually conserved between species but are often recalcitrant to linkage mapping for a lack of readily detectable allelic variations (for chicken-human comparative mapping see Schmid et al. [29]).

Approximately 1000 markers are currently being screened across the $\mathrm{RH}$ panel; a part of them are microsatellite markers anchored on the genetic map and the others are ESTs. This WGRH panel, named ChickRH6, is available to the academic community, upon request to the authors (mmorisso@ toulouse.inra.fr; vignal@toulouse.inra.fr). 


\section{ACKNOWLEDGEMENTS}

We thank Dr Fabienne Pituello for providing 9-day-old chick embryos. This work was aided by a grant from the Département de Génétique Animale, Institut national de la recherche agronomique, France.

\section{REFERENCES}

[1] Abdrakhmanov I., Lodygin D., Geroth P., Arakawa H., Law A., Plachy J., Korn B., Buerstedde J.-M., A large database of chicken bursal ESTs as a resource for the analysis of vertebrate gene function, Genome Res. 10 (2000) 2062-2069.

[2] Bloom S.E., Delany M.E., Muscarella D.E., Constant and variable features of the avian chromosomes, in: Etches R.J., Gibbins A.M.V. (Eds.), Manipulation of the Avian Genome, CRC Press Inc., Orlando, FL, 1993, pp. 39-59.

[3] Clark M.S., Edwards Y.J.K., McQueen H.A., Meek S.E., Smith S., Umrania Y., Warner S., Williams G., Elgar G., Sequence scanning chicken cosmids: a methodology for genome screening, Gene 227 (1999) 223-230.

[4] Clinton M., A rapid protocol for sexing chick embryos (Gallus g. domesticus), Anim. Genet. 25 (1994) 361-362.

[5] Crooijmans R.P.M.A., Vrebalov J., Dijkhof R.J.M., van der Poel J.J., Groenen M.A.M., Two-dimensional screening of the Wageningen chicken BAC library, Mamm. Genome 11 (2000) 360-363.

[6] Don R.H., Cox P.T., Wainwright B.J., Baker K., Mattick J.S., “Touchdown” PCR to circumvent spurious priming during gene amplification, Nucleic Acids Res. 19 (1991) 4008.

[7] Echard G., Gellin J., Gillois M., Localisation des gènes MPI, PKM2, NP sur le chromosome 3 du porc (Sus scrofa L.) et analyse cytogénétique d'une lignée de hamster chinois issue de la DON (wg3h), Genet. Sel. Evol. 16 (1984) 261-270.

[8] Fillon V., Morisson M., Zoorob R., Auffray C., Douaire M., Gellin J., Vignal A., Identification of 16 chicken microchromosomes by molecular markers using two-colour fluorescence in situ hybridization (FISH), Chromosome Res. 6 (1998) 307-313.

[9] Fillon V., Zoorob R., Yerle M., Auffray C., Vignal A., Mapping of the genetically independent chicken major histocompatibility complexes B@ and RFP-Y@ to the same microchromosome by two-color fluorescence in situ hybridization (FISH), Cytogenet. Cell Genet. 75 (1996) 7-9.

[10] Fukagawa T., Hayward N., Yang J., Azzalin C., Griffin D., Stewart A.F., Brown W., The chicken HPRT gene: a counter selectable marker for the DT40 cell line, Nucleic Acids Res. 27 (1999) 1966-1969.

[11] Geisler R., Rauch G.-J., Baier H., van Bebber F., Broß L., Dekens M.P.S., Finger K., Fricke C., Gates M.A., Geiger H., Geiger-Rudolph S., Gilmour D., Glaser S., Gnügge L., Habeck H., Hingst K., Holley S., Keenan J., Kirn A., Knaut H., Lashkari D., Maderspacher F., Martyn U., Neuhauss S., Neumann C., Nicolson T., Pelegri F., Ray R., Rick J.M., Roehl H., Roeser T., Schauerte H.E., Schier A.F., Schönberger U., Schönthaler H.-B., Schutle-Merker S., Seydler C., Talbot W.S., Weiler C., Nüsslein-Volhard C., Haffter P., A radiation hybrid map of the zebrafish genome, Nat. Genet. 23 (1999) 86-89. 
[12] Groenen M.A.M., Cheng H.H., Bumstead N., Benkel B.F., Briles W.E., Burke T., Burt D.W., Crittenden L.B., Dodgson J., Hillel J., Lamont S., Ponce de Leon F.A., Soller M., Takahashi H., Vignal A., A consensus linkage map of the chicken genome, Genome Res. 10 (2000) 137-147.

[13] Gyapay G., Schmitt K., Fizames C., Jones H., Vega-Czarny N., Spillett D., Muselet D., Prud'Homme J.F., Dib C., Auffray C., Morissette J., Weissenbach J., Goodfellow P.N., A radiation hybrid map of the human genome, Hum. Mol. Genet. 5 (1996) 339-346.

[14] Hukriede N.A., Joly L., Tsang M., Miles J., Tellis P., Epstein J.A., Barbazuk W.B., Li F.N., Paw B., Postlethwait J.H., Hudson T.J., Zon L.I., McPherson J.D., Chevrette M., Dawid I.B., Johnson S.L., Ekker M., Radiation hybrid mapping of the zebrafish genome, Proc. Natl. Acad. Sci. USA 96 (1999) 9745-9750.

[15] James M.R., Richard C.W., 3rd, Schott J.-J., Yousry C., Clark K., Bell J., Terwilliger J.D., Hazan J., Dubay C., Vignal A., Agrapart M., Imai T., Nakamura Y., Polymeropoulos M., Weissenbach J., Cox D.R., Lathrop G.M., A radiation hybrid map of 506 STS markers spanning human chromosome 11, Nat. Genet. 8 (1994) 70-76.

[16] Jones H.B., Hybrid selection as a method of increasing mapping power for radiation hybrids, Genome Res. 6 (1996) 761-769.

[17] Kiguwa S.L., Hextall P., Smith A.L., Critcher R., Swinburne J., Millon L., Binns M.M., Goodfellow P.N., McCarthy L.C., Farr C.J., Oakenfull E.A., A horse whole-genome-radiation hybrid panel: Chromosome 1 and 10 preliminary maps, Mamm. Genome 11 (2000) 803-805.

[18] Kwok C., Korn R.M., Davis M.E., Burt D.W., Critcher R., McCarthy L., Paw B.H., Zon L.I., Goodfellow P.N., Schmitt K., Characterization of whole genome radiation hybrid mapping resources for non-mammalian vertebrates, Nucleic Acids Res. 26 (1998) 3562-3566.

[19] Ladjali-Mohammedi K., Bitgood J.J., Tixier-Boichard M., Ponce de Leon F.A., International System for Standardized Avian Karyotypes (ISSAK): standardized banded karyotypes of the domestic fowl (Gallus domesticus), Cytogenet. Cell Genet. 86 (1999) 271-276.

[20] Lee M.-K., Ren C., Ling P., Cox B., Dodgson J.B., Zhang H.-B., Towards a BAC-based physical map of the chicken genome, in: Plant \& Animal Genome IX Conference, 2001, San Diego.

[21] Lunetta K.L., Boehnke M., Lange K., Cox D.R., Experimental design and error detection for polyploid radiation hybrid mapping, Genome Res. 5 (1995) 151163.

[22] McCarthy L.C., Bihoreau M.-T., Kiguwa S.L., Browne J., Watanabe T.K., Hishigaki H., Tsuji A., Kiel S., Webber C., Davis M.E., Knights C., Smith A., Critcher R., Huxtall P., Hudson J.R., Jr., Ono T., Hayashi H., Takagi T., Nakamura Y., Tanigami A., Goodfellow P.N., Lathrop G.M., James M.R., A whole-genome radiation hybrid panel and framework map of the rat genome, Mamm. Genome 11 (2000) 791-795.

[23] McCarthy L.C., Terrett J., Davis M.E., Knights C.J., Smith A.L., Critcher R., Schmitt K., Hudson J., Spurr N.K., Goodfellow P.N., A first-generation whole genome-radiation hybrid map spanning the mouse genome, Genome Res. 7 (1997) 1153-1161. 
[24] McQueen H.A., Siriaco G., Bird A.P., Chicken microchromosomes are hyperacetylated, early replicating, and gene rich, Genome Res. 8 (1998) 621-630.

[25] Morisson M., Pitel F., Fillon V., Pouzadoux A., Bergé R., Vit J.-P., Zoorob R., Auffray C., Gellin J., Vignal A., Integration of chicken cytogenetic and genetic maps: 18 new polymorphic markers isolated from BAC and PAC clones, Anim. Genet. 29 (1998) 348-355.

[26] Murphy W.J., Menotti-Raymond M., Lyons L.A., Thompson M.A., O’Brien S.J., Development of a feline whole genome radiation hybrid panel and comparative mapping of human chromosome 12 and 22 loci, Genomics 57 (1999) 1-8.

[27] Olivier M., Aggarwal A., Allen J., Almendras A.A., Bajorek E.S., Beasley E.M., Brady S.D., Bushard J.M., Bustos V.I., Chu A., Chung T.R., De Witte A., Denys M.E., Dominguez R., Fang N.Y., Foster B.D., Freudenberg R.W., Hadley D., Hamilton L.R., Jeffrey T.J., Kelly L., Lazzeroni L., Levy M.R., Lewis S.C., Liu X., Lopez F.J., Louie B., Marquis J.P., Martinez R.A., Matsuura M.K., Misherghi N.S., Norton J.A., Olshen A., Perkins S.M., Perou A.J., Piercy C., Piercy M., Qin F., Reif T., Sheppard K., Shokoohi V., Smick G.A., Sun W.-L., Stewart E.A., Tejeda J.F., Tran N.M., Trejo T., Vo N.T., Yan S.C.M., Zierten D.L., Zhao S., Sachidanandam R., Trask B.J., Myers R.M., Cox D.R., A high-resolution radiation hybrid map of the human genome draft sequence, Science 291 (2001) 1298-1302.

[28] Rodionov A.V., Micro versus macro: a review of structure and functions of avian micro- and macrochromosomes, Russ. J. Genet. 32 (1996) 517-527.

[29] Schmid M., Nanda I., Guttenbach M., Steinlein C., Hoehn H., Schartl M., Haaf T., Weigend S., Fries R., Buerstedde J.-M., Wimmers K., Burt D.W., Smith J., A’Hara S., Law A., Griffin D.K., Bumstead N., Kaufman J., Thomson P.A., Burke T., Groenen M.A.M., Crooijmans R.P.M.A., Vignal A., Fillon V., Morisson M., Pitel F., Tixier-Boichard M., Ladjali-Mohammedi K., Hillel J., Mäki-Tanila A., Cheng H.H., Delany M.E., Burnside J., Mizuno S., First report on chicken genes and chromosomes 2000, Cytogenet. Cell Genet. 90 (2000) 169-218.

[30] Smith J., Bruley C.K., Paton I.R., Dunn I., Jones C.T., Windsor D., Morrice D.R., Law A.S., Masabanda J., Sazanov A., Waddington D., Fries R., Burt D.W., Differences in gene density on chicken macrochromosomes and microchromosomes, Anim. Genet. 31 (2000) 96-103.

[31] Smith J., Paton I.R., Bruley C.K., Windsor D., Burke D., Ponce de Leon F.A., Burt D.W., Integration of the genetic and physical maps of the chicken macrochromosomes, Anim. Genet. 31 (2000) 20-27.

[32] Solari A.J., Dresser M.E., High-resolution cytological localization of the Xho1 and EcoR1 repeat sequences in the pachytene $\mathrm{ZW}$ bivalent of the chicken, Chromosome Res. 3 (1995) 87-93.

[33] Stewart E.A., McKusick K.B., Aggarwal A., Bajorek E., Brady S., Chu A., Fang N., Hadley D., Harris M., Hussain S., Lee R., Maratukulam A., O’Connor K., Perkins S., Piercy M., Qin F., Reif T., Sanders C., She X., Sun W.-L., Tabar P., Voyticky S., Cowles S., Fan J.-B., Mader C., Quackenbush J., Myers R.M., Cox D.R., An STS-based radiation hybrid map of the human genome, Genome Res. 7 (1997) 422-433. 
[34] Tirunagaru V.G., Sofer L., Cui J., Burnside J., An expressed sequence tag database of T-cell-enriched activated chicken splenocytes: sequence analysis of 5251 clones, Genomics 66 (2000) 144-151.

[35] Vignaux F., Hitte C., Priat C., Chuat J.-C., Andre C., Galibert F., Construction and optimization of a dog whole-genome radiation hybrid panel, Mamm. Genome 10 (1999) 888-894.

[36] Walter M.A., Spillett D.J., Thomas P., Weissenbach J., Goodfellow P.N., A method for constructing radiation hybrid maps of whole genomes, Nat. Genet. 7 (1994) 22-28.

[37] Womack J.E., Johnson J.S., Owens E.K., Rexroad C.E., 3rd, Schläpfer J., Yang Y.-P., A whole-genome radiation hybrid panel for bovine gene mapping, Mamm. Genome 8 (1997) 854-856.

[38] Yerle M., Pinton P., Robic A., Alfonso A., Palvadeau Y., Delcros C., Hawken R., Alexander L., Beattie C., Schook L., Milan D., Gellin J., Construction of a whole-genome radiation hybrid panel for high-resolution gene mapping in pigs, Cytogenet. Cell Genet. 82 (1998) 182-188.

To access this journal online: www.edpsciences.org 